\title{
Extracellular matrix modulates the biological effects of melatonin in mesenchymal stem cells
}

\author{
Fan $\mathrm{He}^{1,2,3, *}$, Xiaozhen Liu, ${ }^{1, *}$, Ke Xiong ${ }^{4}$, Sijin Chen ${ }^{4}$, Long Zhou ${ }^{2,3}$, Wenguo Cui ${ }^{2,3}$, \\ Guoqing $\mathrm{Pan}^{2,3}$, Zong-Ping Luo ${ }^{2,3}$, Ming $\mathrm{Pei}^{5}$ and Yihong Gong' \\ ${ }^{1}$ School of Engineering, Sun Yat-sen University, No. 132 East Waihuan Road, Guangzhou Higher Education Mega \\ Center, Guangzhou 510006, China \\ ${ }^{2}$ Orthopaedic Institute, Soochow University, No. 708 Renmin Road, Suzhou, Jiangsu 215007, China \\ ${ }^{3}$ Department of Orthopaedics, The First Affiliated Hospital of Soochow University, Suzhou 215006, China \\ ${ }^{4}$ Nanfang Hospital, Southern Medical University, Guangzhou 510515, China \\ ${ }^{5}$ Stem Cell and Tissue Engineering Laboratory, Department of Orthopaedics, West Virginia University, Morgantown, \\ West Virginia 26506, USA \\ ${ }^{*}$ (F He and X Liu contributed equally to this work)
}

Correspondence should be addressed to $\mathrm{F}$ He or Y Gong Emails fanhe@suda.edu.cn or gongyih@mail.sysu.edu.cn

\begin{abstract}
Both self-renewal and lineage-specific differentiation of mesenchymal stem cells (MSCs) are triggered by their in vivo microenvironment including the extracellular matrix (ECM) and secreted hormones. The ECM may modulate the physiological functions of hormones by providing binding sites and by regulating downstream signaling pathways. Thus, the purpose of this study was to evaluate the degree of adsorption of melatonin to a natural cell-deposited ECM and the effects of this interaction on the biological functions of melatonin in human bone marrow-derived MSCs (BM-MSCs). The fibrillar microstructure, matrix composition, and melatonin-binding affinity of decellularized ECM were characterized. The cell-deposited ECM improved melatonin-mediated cell proliferation by $31.4 \%$, attenuated accumulation of intracellular reactive oxygen species accumulation, and increased superoxide dismutase (SOD) mRNA and protein expression. Interaction with ECM significantly enhanced the osteogenic effects of melatonin on BM-MSCs by increasing calcium deposition by $30.5 \%$, up-regulating osteoblast-specific gene expression and down-regulating matrix metalloproteinase (MMP) expression. The underlying mechanisms of these changes in expression may involve intracellular antioxidant enzymes, because osteoblast-specific genes were down-regulated, whereas MMP expression was up-regulated, in the presence of SOD-specific inhibitors. Collectively, our findings indicate the importance of native ECM in modulating the osteoinductive and antioxidant effects of melatonin and provide a novel platform for studying the biological actions of growth factors or hormones in a physiologically relevant microenvironment. Moreover, a better understanding of the enhancement of MSC growth and osteogenic differentiation resulting from the combination of ECM and melatonin could improve the design of graft substitutes for skeletal tissue engineering.
\end{abstract}

\section{Key Words}

- decellularized extracellular matrix

- melatonin

- mesenchymal stem cells

- superoxide dismutase
Journal of Endocrinology

(2014) 223, 167-180 http://joe.endocrinology-journals.org DOI: $10.1530 / \mathrm{JOE}-14-0430$
() 2014 Society for Endocrinology Printed in Great Britain
Published by Bioscientifica Ltd 


\section{Introduction}

The pluripotency of mesenchymal stem cells (MSCs) makes them a promising cell source for tissue engineering and regenerative medicine. In addition, MSCs can easily be isolated from various adult tissues, especially from the bone marrow (BM; Pittenger et al. 1999); MSCs in the BM (BM-MSCs) were discovered on the basis of their ability to attach to culture plates. Their extensive proliferation capacity, multilineage differentiation potential, and ability to evade the immune system have stimulated great interest in the possibility of utilizing MSCs in clinical applications (Jiang et al. 2002). BM-MSCs most often reside in the BM microenvironment, where extrinsic or intrinsic signaling factors can drive BM-MSCs out of quiescence and toward replication or differentiation. This microenvironment consists of a calcified extracellular matrix (ECM), growth factors, cytokines, platelet-rich plasma, hormones, and several types of cells such as osteocytes, osteoclasts, and hematopoietic cells (Hamilton \& Campbell 1991).

Bone structures undergo a continuous remodeling process of resorption and formation via osteoclasts and osteoblasts, which are responsible for destroying the old bone architecture and building a new one respectively (Lopez-Martinez et al. 2012). Osteoporosis, a bone disease characterized by low bone mass and micro-architectural deterioration, is caused by dysfunction of both cell types (Sanchez-Barcelo et al. 2010). Along with systemic hormones and growth factors, melatonin ( $\mathrm{N}$-acetyl-5methoxytryptamine) is an important mediator in bone formation and mineralization, and ultimately regulates the balance of bone remodeling (Cardinali et al. 2003). Melatonin is synthesized and secreted by the pineal gland; it is present at high levels in the BM (Tan et al. 1999) and is known for its antioxidant properties (Poeggeler et al. 1993). Specifically, it reduces oxidative damage by directly scavenging free radicals and thereby protects cells from pro-inflammatory cytokines (Liu et al. 2013). The beneficial effects of melatonin on bone metabolism have been detected in numerous studies. As a night supplement, melatonin improves bone health and prevents bone loss in perimenopausal women without major side effects (Kotlarczyk et al. 2012). In addition, melatonin exerts an osteoinductive effect by promoting osteogenic maturation of human adult MSCs (Zhang et al. 2010), as well as cartilage matrix synthesis by articular chondrocytes (Pei et al. 2009).

The ECM plays a critical role not only in providing the architectural framework and giving rise to the biomechanical properties of bone, but also in regulating
BM-MSC survival, adhesion, migration, proliferation, and differentiation. In recent studies, ECM has been treated to remove the cells that deposited it, and has been then utilized to facilitate large-scale and rapid expansion of MSCs; MSCs cultured in such ECM retain their stem cell properties (He et al. 2009). It has been proposed that this decellularized ECM creates an in vitro extracellular microenvironment for stem cells that is capable of influencing their proliferation, lineage-specific differentiation, and cell-matrix interactions (He \& Pei 2013, He et al. 2013). More importantly, growth-promoting factors have been found to bind to ECM (Chen et al. 2007) and this adsorption onto decellularized ECM enhances the osteogenic maturation of calvarial osteoblasts (Bhat et al. 2011). However, studies investigating the interplay between bone ECM and melatonin are rare, and the effects of this interaction on stem cell behaviors need to be elucidated. Therefore, the aim of this study was to evaluate the role of natural ECM in modulating the biological functions of melatonin in MSCs.

We proposed the hypothesis that, relative to unbound melatonin, melatonin bound to decellularized ECM would exhibit distinct antioxidant and osteoinductive effects on BM-MSCs. To test this hypothesis, BM-MSCs were cultured on decellularized ECM, or on tissue culture polystyrene (TCPS), with or without melatonin. Production of intracellular reactive oxygen species (ROS), antioxidant enzyme activity, cellular proliferation, osteogenic differentiation, and matrix degradation were assayed under these conditions.

\section{Materials and methods}

\section{Reagents}

BM-MSCs were purchased from the American Type Culture Collection (ATCC, Manassas, VA, USA). TCPS plates were purchased from Costar (Corning, Tewksbury, MA, USA). Protease inhibitor tablets, fetal bovine serum (FBS), alpha minimum essential medium ( $\alpha$-MEM), and DMEM were purchased from Thermo Fisher Scientific (Waltham, MA, USA). Penicillin, streptomycin, and TRIzol reagent were purchased from Invitrogen. Gelatin, glutaraldehyde, ethanolamine, Triton $\mathrm{X}-100, \mathrm{NH}_{4} \mathrm{OH}$, DNase I, BSA, papain, methanol, paraformaldehyde, dexamethasone, L-ascorbic acid, $\beta$-glycerophosphate, melatonin, diethyldithiocarbamate (DDC), 2-methoxyestradiol (2-ME), and 2',7'-dichlorofluorescein diacetate (DCF-DA)

Published by Bioscientifica Ltd 
were purchased from Sigma Chemical Co. Primary antibodies against type I collagen, type III collagen, fibronectin, laminin, copper-zinc superoxide dismutase (CuZn-SOD/SOD1), manganese superoxide dismutase (Mn-SOD/SOD2), and glyceraldehyde-3-phosphate dehydrogenase (GAPDH) were purchased from Abcam (Cambridge, MA, USA). Primary antibody against decorin was obtained from Santa Cruz Biotechnology. Primary antibody against melatonin was obtained from Biorbyt Ltd (Cambridge, UK).

\section{Preparation of decellularized ECM deposited by BM-MSCs}

The TCPS plates were pretreated with $0.2 \%$ gelatin for $1 \mathrm{~h}$ at $37^{\circ} \mathrm{C}$, and then with $1 \%$ glutaraldehyde and $1 \mathrm{M}$ ethanolamine, sequentially, for $30 \mathrm{~min}$ each, at room temperature. BM-MSCs were seeded on pretreated plates in a growth medium ( $\alpha$-MEM supplemented with $10 \%$ FBS, $100 \mathrm{U} / \mathrm{ml}$ penicillin, and $100 \mu \mathrm{g} / \mathrm{ml}$ streptomycin). Once the cells reached $80-90 \%$ confluence, $100 \mu \mathrm{M}$ of $\mathrm{L}$-ascorbic acid was added, and cells were cultured for an additional 8 days. To obtain acellular ECM, the cultured cells were incubated in an extraction buffer, consisting of PBS, $0.5 \%$ Triton $\mathrm{X}-100$, and $20 \mathrm{mM} \mathrm{NH} \mathrm{N}_{4} \mathrm{OH}$, at a $\mathrm{pH}$ of 7.4 , for $5 \mathrm{~min}$, and then treated with $100 \mathrm{U} / \mathrm{ml}$ of DNase I for $1 \mathrm{~h}$ at $37^{\circ} \mathrm{C}$. Decellularized ECM was washed with PBS and stored under sterile conditions at $4{ }^{\circ} \mathrm{C}$.

\section{Ultra-structural characterization of decellularized ECM by transmission electron microscopy}

The decellularized ECM was fixed in a mixture of $2.5 \%$ glutaraldehyde and $2 \%$ paraformaldehyde, and then incubated in $1 \% \mathrm{OsO}_{4}$ (Sigma) for $1.5 \mathrm{~h}$ at room temperature. After rinsing with PBS, ECM was dehydrated in increasing concentrations of ethanol (50, 70, 80, 90, and 100\%) and then soaked in acetone (Sigma) for $15 \mathrm{~min}$. After overnight incubation in an embedding medium (eponate 12, DDSA, NMA, and DMP-30, Sigma), the sample was polymerized at $60{ }^{\circ} \mathrm{C}$ for $48 \mathrm{~h}$. Sections, of 50-nm thickness, were cut with an ultramicrotome (Leica EM UC6; Leica Microsystems, Wetzlar, Germany). The samples were double-stained with uranyl acetate and lead citrate, and then examined with a transmission electron microscope at $80 \mathrm{kV}$ (Tecnai G2 spirit TWIN; FEI Company, Hillsboro, OR, USA).

\section{Morphological characterization of decellularized ECM by scanning electron microscopy}

The decellularized ECM was fixed in $2.5 \%$ glutaraldehyde and dehydrated in increasing concentrations of ethanol
$(50,75,80,95$, and $100 \%)$. The morphology of decellularized ECM was examined with a scanning electron microscope (SEM; S-520; Hitachi High-Technologies).

\section{Immunofluorescence staining}

The cell-deposited ECM was first fixed in ice-cold methanol and then blocked in 1\% BSA, and then incubated in appropriately diluted primary antibodies. After rinsing with PBS, ECM was incubated in secondary antibody (Alexa Fluor 488 donkey anti-mouse or antirabbit IgG $(\mathrm{H}+\mathrm{L})$, Invitrogen). The cell nuclei were stained using ProLong Gold Antifade Reagent with DAPI (Invitrogen). The fluorescence images were obtained using an Olympus IX71 microscope (Olympus Corporation) and processed with Image-ProPlus Software (Media Cybernetics, Inc., Rockville, MD, USA).

\section{HPLC-based assay for melatonin adsorption to decellularized ECM}

The decellularized ECM or TCPS was exposed to $100 \mu \mathrm{M}$ melatonin in PBS (pH 7.4) at $37^{\circ} \mathrm{C}$ in $5 \% \mathrm{CO}_{2}$. At different time points $(0,0.5,1,2,4,6,12,24,48$, and $72 \mathrm{~h})$, the concentration of melatonin remaining in solution was determined by HPLC (Agilent Technologies, Santa Clara, CA, USA) with a ZORBAX Eclipse XDB-C18 column (Agilent Technologies). Three samples, each $10 \mu \mathrm{l}$ in volume, were injected at each time point, and the mobile phase $(55 \%$ methanol $/ 45 \%$ water, $\mathrm{v} / \mathrm{v})$ was delivered at $1.0 \mathrm{ml} / \mathrm{min}$. The melatonin in the column effluent was measured using a u.v. detector at $222 \mathrm{~nm}$.

\section{Cell culture of BM-MSCs}

The BM-MSCs were cultured in a growth medium at $37^{\circ} \mathrm{C}$ in $5 \% \mathrm{CO}_{2}$ and were detached using $0.25 \%$ Trypsin-EDTA solution (Invitrogen). To investigate the effect of decellularized ECM on melatonin-mediated cell proliferation, BM-MSCs were cultured in tissue culture plates with either a conventional TCPS surface or a layer of ECM, either without melatonin or supplemented with $10 \mathrm{nM}, 1 \mu \mathrm{M}$, or $100 \mu \mathrm{M}$ melatonin. The cells were cultured for 5 days, and the medium was replaced every other day.

\section{Fluorescein diacetate labeling}

The BM-MSCs were washed with PBS and then incubated in $5 \mu \mathrm{g} / \mathrm{ml}$ fluorescein diacetate (FDA) solution at $37^{\circ} \mathrm{C}$ for $10 \mathrm{~min}$. The cells were washed again with PBS,

Published by Bioscientifica Ltd 
and the fluorescence images were captured with an Olympus IX71 microscope and processed with ImageProPlus Software.

\section{Cell proliferation assay}

The BM-MSCs were seeded on TCPS or on ECM, and cultured in $0 \mathrm{nM}, 10 \mathrm{nM}, 1 \mu \mathrm{M}$, or $100 \mu \mathrm{M}$ melatonin, in quintuplicate wells. After 5 days, the total DNA content in each well, as a proxy for the number of cells, was measured with the Quant-iT PicoGreen dsDNA Assay Kit (P7589, Invitrogen), following the manufacturer's instructions. Briefly, $200 \mu \mathrm{l}$ of papain lysis buffer $(125 \mu \mathrm{g} / \mathrm{ml}$ in PBS $)$ was added to each well, and the cells were lysed at $60^{\circ} \mathrm{C}$ for $4 \mathrm{~h}$. Equal quantities of lysates and of PicoGreen reagent were added to the corresponding wells of a 96-well plate, and resulting samples were incubated in the dark, at room temperature, for $5 \mathrm{~min}$, to bind the fluorescent dye to lysate DNA. Fluorescence of the samples was measured using a SynergyMx multi-mode microplate reader (BioTek, Winooski, VT, USA) at 485/520 nm (excitation/emission), alongside a standard curve.

\section{Measurement of intracellular ROS production}

Intracellular ROS was quantified by the DCF-DA fluorescence method. Briefly, for each experimental condition, $2 \times 10^{5}$ cells were incubated, in quadruplicate, in $10 \mu \mathrm{M}$ of DCF-DA for $10 \mathrm{~min}$ at $37^{\circ} \mathrm{C}$. The fluorescence intensity of the product of the reaction between DCF-DA and ROS was measured using a BD dual-laser FACSCalibur (BD Biosciences, San Jose, CA, USA), and 10000 events from each cell sample were analyzed using the Windows Multiple Document Interface for Flow Cytometry (WinMDI) 2.9 Software.

\section{SOD activity assay}

The activity of SOD was assessed with a commercially available SOD assay kit (Sigma), according to the manufacturer's instructions. The BM-MSCs were detached and suspended in cell lysis solution to produce four lysates, each from cells cultured on ECM or on TCPS, with or without $100 \mu \mathrm{M}$ melatonin. Total lysate proteins were quantified with a BCA protein assay kit (Beyotime, Haimen, Jiangsu, China). Each lysate was mixed with WST solution from the kit and incubated at $37^{\circ} \mathrm{C}$ for $20 \mathrm{~min}$. Absorbance was measured at $450 \mathrm{~nm}$ using a microplate reader (BioTek).

\section{Antioxidant inhibitor assay}

The cells were cultured on TCPS or on ECM and treated with $50 \mu \mathrm{M}$ DDC, an inhibitor of CuZn-SOD, for $1.5 \mathrm{~h}$, or with $1 \mu \mathrm{M} 2-\mathrm{ME}$, an inhibitor or Mn-SOD, for $24 \mathrm{~h}$ (or were left untreated) before incubation with or without $100 \mu \mathrm{M}$ melatonin (Dumay et al. 2006).

\section{Osteogenic differentiation of BM-MSCs}

The BM-MSCs were cultured in a differentiation medium (DMEM supplemented with 10\% FBS, $100 \mathrm{U} / \mathrm{ml}$ penicillin, $100 \mu \mathrm{g} / \mathrm{ml}$ streptomycin, $0.2 \mathrm{mM}$ L-ascorbic acid, $100 \mathrm{nM}$ dexamethasone, and $10 \mathrm{mM} \beta$-glycerophosphate) for 14 days to induce osteogenic differentiation. ECM calcification (a differentiation marker) was assessed by staining with $0.5 \%$ alizarin red solution (Sigma). To quantify the calcium deposition, the stained cultures were incubated in $500 \mu \mathrm{l}$ of $1 \%$ hydrochloric acid (Sigma) to extract calciumbound alizarin red. Absorbance of the extracted stain was measured at $420 \mathrm{~nm}$ using a microplate reader (BioTek).

\section{Total RNA extraction and real-time RT-PCR}

Total RNA was extracted (from four groups of cells per experimental condition) with TRIzol reagent, and $1 \mu \mathrm{g}$ of total RNA was reverse-transcribed using the PrimeScript RT Reagent Kit (TaKaRa, Mountain View, CA, USA). To quantify the mRNA expression, an amount of cDNA equivalent to $20 \mathrm{ng}$ of total RNA was amplified by real-time PCR using the GoTaq qPCR Master Mix Kit (Promega). Transcription levels of SOD genes (SOD1, encoding CuZn-SOD, and $S O D 2$, encoding Mn-SOD), osteogenic marker genes ( $A L P$, COL1A1, SPP1 (OPN), BGLAP (OCN), SP7 (OSX), and RUNX2), matrix metalloproteinase genes (MMP1 and MMP2), and GAPDH (an internal standard) were evaluated using the primer sequences listed in Table 1. Real-time PCR was carried out using an ABI7500 Real-Time PCR System (Applied Biosystems) following the manufacturer's protocol. Relative transcript levels were calculated as $\chi=2^{-\Delta \Delta C \mathrm{t}}$, in which $\Delta \Delta C \mathrm{t}=\Delta E-\Delta C, \Delta E=C \mathrm{t}_{\mathrm{exp}}-C \mathrm{t}_{\mathrm{GAPDH}}$, and $\Delta C=C \mathrm{t}_{\mathrm{ct} 1}-C \mathrm{t}_{\mathrm{GAPDH}}\left(C \mathrm{t}_{\mathrm{exp}}\right.$, the threshold cycle for the gene of interest under experimental conditions; $\mathrm{Ct}_{\mathrm{GAPDH}}$, the threshold cycle for GAPDH; $\mathrm{CT}_{\mathrm{ct} 1}$, the threshold cycle for the gene of interest under control conditions).

\section{Western blotting analysis}

The BM-MSCs were lysed in ice-cold cell lysis buffer (Beyotime), containing protease inhibitors, and the

Published by Bioscientifica Ltd 
Table 1 Primers used for real-time RT-PCR

\begin{tabular}{|c|c|c|}
\hline Gene & Primer sequence $\left(5^{\prime}-3^{\prime}\right)$ & GenBank accession no. \\
\hline \multicolumn{3}{|c|}{ The internal standard gene } \\
\hline GAPDH & $\begin{array}{l}\text { F: AGAAAAACCTGCCAAATATGATGAC } \\
\text { R: TGGGTGTCGCTGTTGAAGTC }\end{array}$ & NM_002046 \\
\hline \multicolumn{3}{|c|}{ Superoxide dismutase genes } \\
\hline SOD1/CuZn-SOD & $\begin{array}{l}\text { F: GGTGGGCCAAAGGATGAAGAG } \\
\text { R: CCACAAGCCAAACGACTTCC }\end{array}$ & NM_000454.4 \\
\hline SOD2/Mn-SOD & $\begin{array}{l}\text { F: GGGGATTGATGTGTGGGAGCACG } \\
\text { R: AGACAGGACGTTATCTTGCTGGGA }\end{array}$ & BC012423.1 \\
\hline \multicolumn{3}{|c|}{ Osteogenic marker genes } \\
\hline COL1A1 & $\begin{array}{l}\text { F: CAGCCGCTTCACCTACAGC } \\
\text { R: TTTTGTATTCAATCACTGTCTTGCC }\end{array}$ & NM_000088.3 \\
\hline$A L P$ & $\begin{array}{l}\text { F: AGCACTCCCACTTCATCTGGAA } \\
\text { R: GAGACCCAATAGGTAGTCCACATTG }\end{array}$ & NM_000478.3 \\
\hline SPP1 & $\begin{array}{l}\text { F: GCGAGGAGTTGAATGGTG } \\
\text { R: CTTGTGGCTGTGGGTTTC }\end{array}$ & NM_001251830.1 \\
\hline$B G L A P$ & $\begin{array}{l}\text { F: GAGCCCCAGTCCCCTACC } \\
\text { R: GACACCCTAGACCGGGCCGT }\end{array}$ & NM_001199662.1 \\
\hline$R U N X 2$ & $\begin{array}{l}\text { F: AGAAGGCACAGACAGAAGCTTGA } \\
\text { R: AGGAATGCGCCCTAAATCACT }\end{array}$ & NM_001015051.3 \\
\hline SP7 & $\begin{array}{l}\text { F: CACTCACACCCGGGAGAAGA } \\
\text { R: GGTGGTCGCTTCGGGTAAA }\end{array}$ & NM_152860.1 \\
\hline \multicolumn{3}{|c|}{ Matrix metalloproteinase genes } \\
\hline MMP1 & $\begin{array}{l}\text { F: GGGGCTTTGATGTACCCTAGC } \\
\text { R: TGTCACACGCTTTTGGGGTTT }\end{array}$ & NM_001166229 \\
\hline MMP2 & $\begin{array}{l}\text { F: GATACCCCTTTGACGGTAAGGA } \\
\text { R: CCTTCTCCCAAGGTCCATAGC }\end{array}$ & NM_001127891.1 \\
\hline
\end{tabular}

protein concentration in cell extracts was quantified using a BCA protein assay kit (Beyotime). Equal amounts of protein from each extract were denatured and resolved using a 10\% polyacrylamide gel, and then transferred by electrophoresis onto a nitrocellulose membrane. The membrane was incubated in diluted primary antibodies at $4{ }^{\circ} \mathrm{C}$, overnight. A GAPDH antibody, detected using mouse monoclonal anti-GAPDH antibody, served as loading control. The membranes were then incubated in HRP-conjugated goat anti-mouse or anti-rabbit secondary antibodies (Thermo Fisher Scientific). The membranes were developed using SuperSignal West Femto Maximum Sensitivity Substrate and CL-XPosure Film (Thermo Fisher Scientific). The intensity of bands was quantified using the ImageJ Software (National Institutes of Health, Bethesda, MD, USA).

\section{Statistical analyses}

All data were expressed as the mean \pm s.E.M. Statistical significances of differences between two groups were determined by one-way ANOVA followed by Student's unpaired $t$-test, using the SPSS 13.0 Statistical Software (SPSS, Inc.). A $P$ value of $<0.05\left(^{*}\right)$ or $\left.<0.01{ }^{* *}\right)$ was considered to be statistically significant.

\section{Results}

\section{Characterization of decellularized ECM}

Before testing the effects of melatonin adsorption to ECM on BM-MSCs, it was important to assay the ECM protein integrity and melatonin-binding capacity. The BM-MSCs were induced to deposit ECM and were then removed. Results obtained using immunofluorescence staining of the resulting decellularized ECM confirmed that several representative protein components remained intact throughout the decellularization process, including type I collagen, type III collagen, fibronectin, and laminin. Furthermore, DAPI staining confirmed that the decellularization procedure successfully removed the original ECMdepositing cells and any cellular residues. Decorin, a small proteoglycan found in cytoplasm or pericellular matrix, was not observed in the decellularized ECM (Fig. 1A). Transmission electron microscopy (TEM) analysis revealed the ultrastructure of collagen fibers and basement membrane in decellularized ECM (Fig. 1B). The diameter of a single collagen fiber was determined to be $15.8 \pm$ $2.6 \mathrm{~nm}$, and the basement membrane appeared to be composed of laminin (Fig. 1C). In addition, as observed using SEM, the ECM microstructure was composed of

Published by Bioscientifica Ltd 

$\begin{array}{ll}\text { A } & \text { COLI } \\ \text { FITC/DAPI } & \\ - & \end{array}$

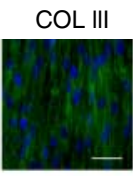
FITC/DAPI -

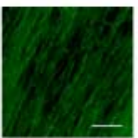

B

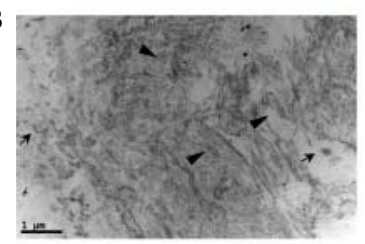

D

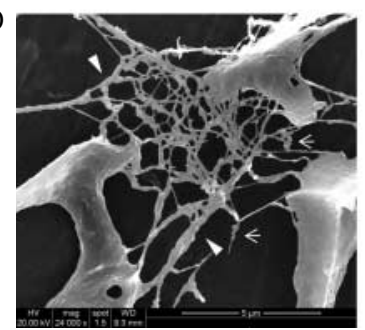

FN
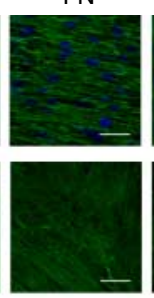

C

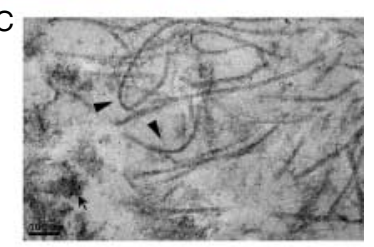

E

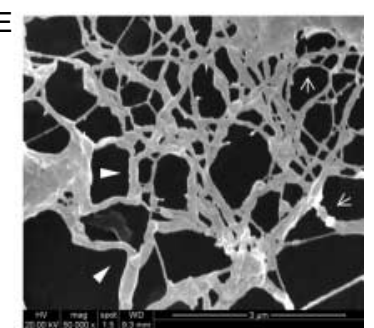

Figure 1

Characterization of decellularized extracellular matrix (ECM). (A) Immunofluorescence staining of matrix proteins (green) in ECM, and of cell nuclei (blue) of original ECM-depositing cells. The cell-deposited ECM was examined before (upper panels) and after (lower panels) decellularization. Scale bars $=50 \mu \mathrm{m}$. COL I, type I collagen; COL III, type III collagen; $\mathrm{FL}$, fibronectin; LN, laminin; DCN, decorin. (B and C) Representative TEM images of decellularized ECM at low and high magnification. The collagen fibers (black arrowheads) and basement laminin (black arrows) were observed in decellularized ECM. Scale bar $=1 \mu \mathrm{m}$ in (B). Scale bar $=100 \mathrm{~nm}$ in (C). (D and E) Representative scanning electron microscopy (SEM) images of decellularized ECM at low and high magnification. Bundles of fibrillar collagen fibers (white arrowheads) and beaded fibers (white arrows) were observed. Scale bar $=5 \mu \mathrm{m}$ in (D). Scale bar $=3 \mu \mathrm{m}$ in (E). A full colour version of this figure is available via http://dx.doi.org/10.1530/JOE-14-0430.

net-like lattices, which consisted of small bundles of collagen fibers (Fig. 1D). The average diameter of these collagen fibrils was $301.8 \pm 90.7 \mathrm{~nm}$ and proteoglycans appeared to be attached to the fibrils, forming beaded filaments (Fig. 1E).

\section{Adsorption capacity for melatonin of decellularized ECM}

We next examined the adsorption of melatonin to decellularized ECM by immunofluorescence and by HPLC. TCPS plates or plates layered with ECM were treated with $100 \mu \mathrm{M}$ of melatonin for $72 \mathrm{~h}$, and then the bound melatonin was visualized by immunofluorescence staining. Melatonin was detected on decellularized ECM (Fig. 2A), but not on TCPS plates (results not shown).

To assess the adsorption capacity of ECM for melatonin, the concentration of melatonin remaining in solution over time was quantified by HPLC and normalized to the initial concentration. In TCPS plates, 95.4-97.9\% of the melatonin remained in solution, compared with $71.1-87.4 \%$ in ECM-layered plates, indicating that decellularized ECM provides binding sites for melatonin (Fig. 2B).

A

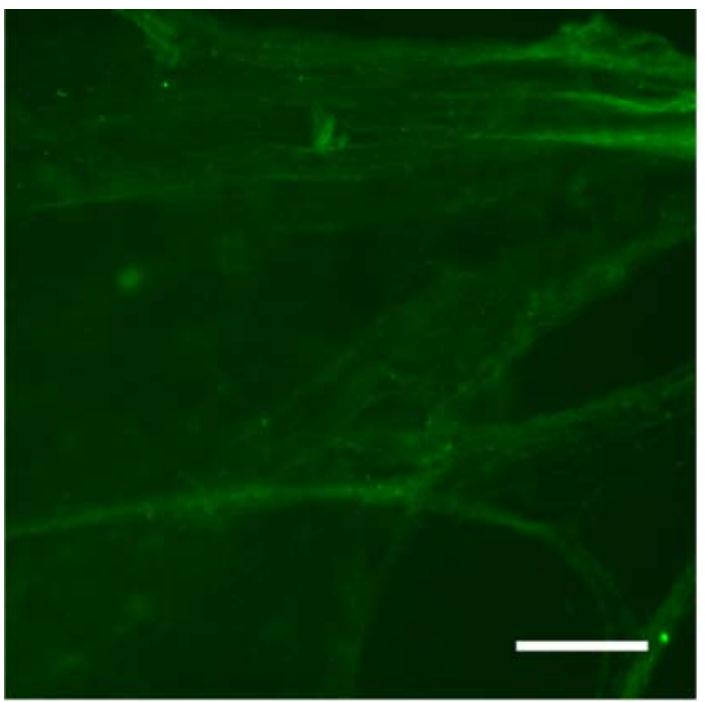

B

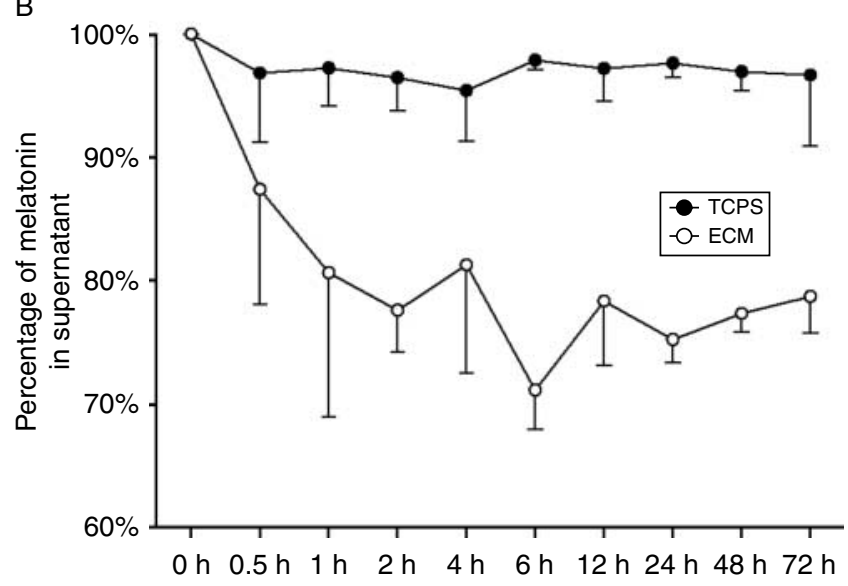

Figure 2

The adsorption of melatonin to decellularized extracellular matrix (ECM) was assessed by immunofluorescence staining and HPLC. (A) Decellularized ECM was treated with $100 \mu \mathrm{M}$ melatonin for $72 \mathrm{~h}$, and the binding of melatonin to ECM was confirmed by immunofluorescence staining. Scale bar $=50 \mu \mathrm{m}$. (B) The concentration of melatonin remaining in solution was assessed by HPLC assay at $0,0.5,1,2,4,6,12,24,48$, and $72 \mathrm{~h}$ after addition of melatonin to tissue culture polystyrene (TCPS) plates or to plates layered with decellularized ECM. The percentage of melatonin was normalized to the initial concentration (concentration at $0 \mathrm{~h}$ ). Data are expressed as the mean \pm S.E.M. of three independent experiments. A full colour version of this figure is available via http://dx.doi.org/10.1530/JOE-14-0430. 


\section{Decellularized ECM modulated melatonin-mediated effects on cell proliferation, ROS production, and SOD}

To determine the effect of ECM on melatonin-mediated cell proliferation, BM-MSCs were cultured on TCPS or on ECM, supplemented with different dosages of melatonin or left unsupplemented. BM-MSCs exhibited uniform, spindle-like morphology on ECM, and multiplied to a higher cell density on ECM than on TCPS (Fig. 3A). The latter phenotype was due to accelerated replication; cells plated on ECM demonstrated 5.4 times greater cell proliferation, in a DNA-content-based assay, than cells plated on TCPS. At the concentrations of $10 \mathrm{nM}, 1 \mu \mathrm{M}$, or $100 \mu \mathrm{M}$, melatonin did not affect the growth of BM-MSCs cultured on TCPS, but did increase the growth rate of cells cultured on ECM in a dose-dependent manner. Treatment with $100 \mu \mathrm{M}$ of melatonin significantly enhanced cell proliferation, by $31.4 \%$, of BMMSCs grown on ECM $(828.3 \pm 43.2 \mathrm{ng}$ DNA/well with melatonin treatment versus $630.2 \pm 39.0 \mathrm{ng} \mathrm{DNA} /$ well without; Fig. 3B).

Next, intracellular ROS production in BM-MSCs was analyzed by DCF fluorescence using flow cytometry (Fig. 4A). With the addition of melatonin, the average level of ROS decreased by $30.1 \%$ in BM-MSCs cultured on TCPS, and diminished further in cells grown on ECM and in melatonin-supplemented cells grown on ECM (Fig. 4B). We then examined the activity and expression of SOD. Treatment with melatonin or growth on ECM, significantly elevated the total activity of SOD, by 10.8 and $20.6 \%$, respectively, relative to untreated and TCPScultured cells (Fig. 4C), but SOD activity was not further elevated significantly in melatonin-treated and ECMcultured cells (Fig. 4C). The cells cultured on ECM had significantly higher levels of SOD1 expression, by $17.8 \%$, compared with cells grown on TCPS (Fig. 4D). With regard to the expression of SOD2, ECM elevated the level of transcription by $15.7 \%$ compared with the cells grown on TCPS. Melatonin treatment augmented the transcription of SOD2 by $14.2 \%$ in the cells grown on TCPS and by $18.1 \%$ in the cells grown on ECM (Fig. 4E). Since SOD enzymes play a pivotal role in neutralizing free radicals, we examined the expression of SOD1 and SOD2 proteins. Treatment with $100 \mu \mathrm{M}$ melatonin significantly up-regulated the expression of SOD1 (by $41.2 \%$ in TCPS-cultured cells and by $84.0 \%$ in ECM-cultured cells) and up-regulated the level of SOD2 in BM-MSCs grown on decellularized ECM, by $48.5 \%$ (Fig. 4F and G).

\section{Decellularized ECM enhanced osteoinductive effects of melatonin}

The BM-MSCs were induced toward osteogenesis on TCPS or on ECM, with or without treatment with melatonin.

A
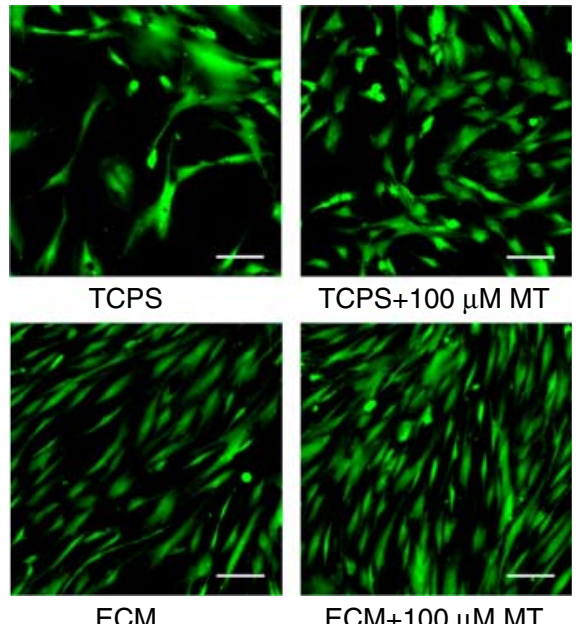

TCPS+100 $\mu \mathrm{M}$ MT

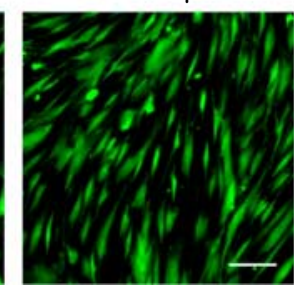

$\mathrm{ECM}+100 \mu \mathrm{M} \mathrm{MT}$

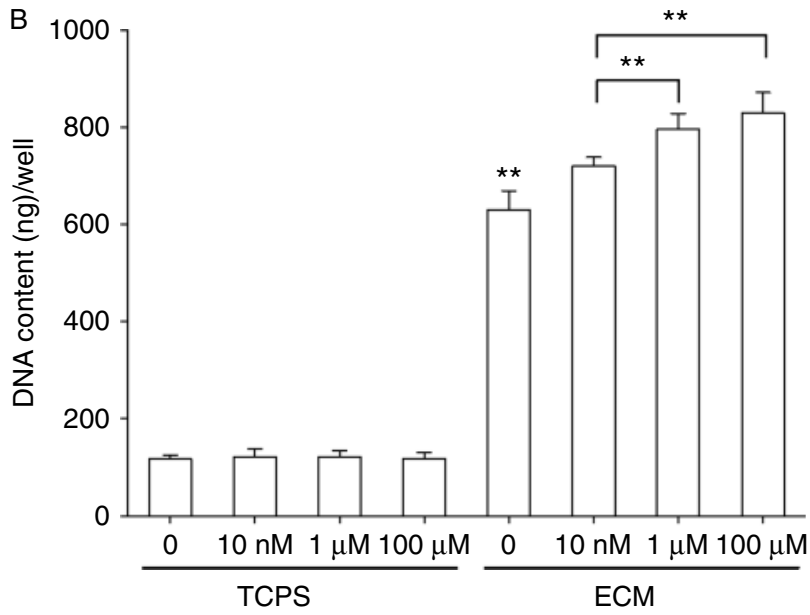

Figure 3

Decellularized extracellular matrix (ECM) enhanced melatonin-mediated proliferative effects on bone-marrow-derived mesenchymal stem cells (BM-MSCs). (A) BM-MSCs were cultured in 12-well plates in a growth medium on tissue culture polystyrene (TCPS) or on decellularized ECM in the presence or absence of $100 \mu \mathrm{M}$ melatonin. The cells were labeled with fluorescein diacetate to examine the cellular morphology and density. Scale bars $=100 \mu \mathrm{m}$. (B) The BM-MSCs showed a dose response to melatonin, with respect to cell proliferation, when cultured on decellularized ECM, but not when cultured on TCPS. The BM-MSCs were cultured on TCPS or on decellularized ECM in the absence of melatonin or with $10 \mathrm{nM}, 1 \mu \mathrm{M}$, or $100 \mu \mathrm{M}$ melatonin. After continuous culture for 5 days, DNA quantification analysis was conducted to measure the cell proliferation of BM-MSCs. Melatonin did not affect proliferation of BM-MSCs grown on TCPS, but the cells grown on decellularized ECM exhibited a dose-dependent increase in cell proliferation with melatonin. Data are expressed as the mean \pm S.E.M. of five independent experiments $(* * P<0.01)$. A full colour version of this figure is available via http://dx.doi.org/10.1530/ JOE-14-0430.

Published by Bioscientifica Ltd. 

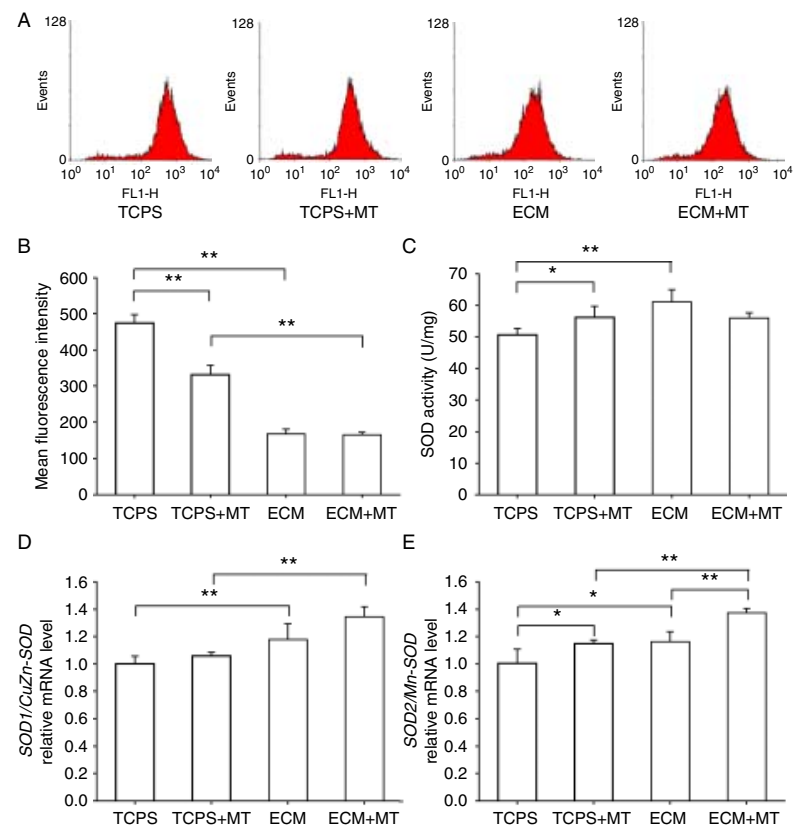

E
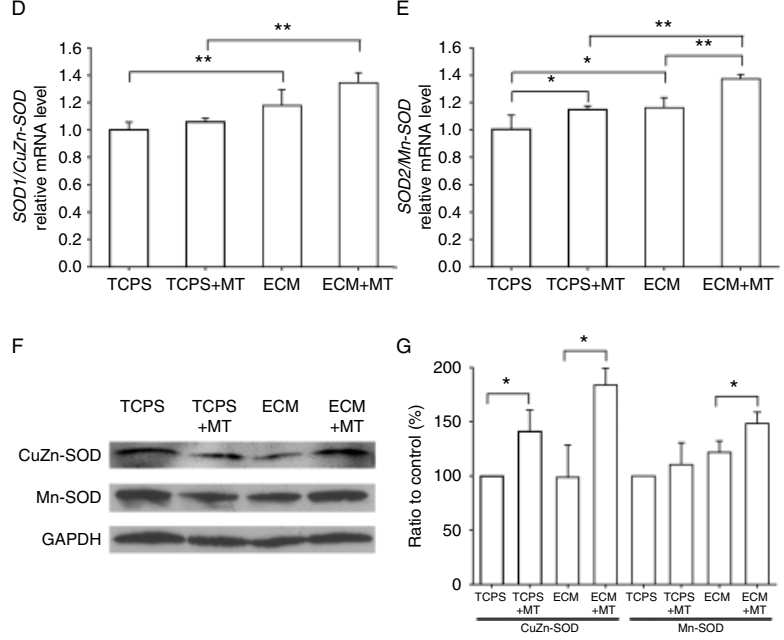

Figure 4

Decellularized extracellular matrix (ECM)-modulated melatonin-mediated effects on intracellular reactive oxygen species (ROS), superoxide dismutase (SOD) activity, and expression of SOD1/CuZn-SOD and SOD2/Mn-SOD. The dosage of melatonin was $100 \mu \mathrm{M}$. (A and B) Intracellular ROS production, as assessed by flow cytometry, was lower in bone-marrow-derived mesenchymal stem cells (BM-MSCs) grown on ECM and supplemented with melatonin. (C) Decellularized ECM increased SOD activity in BM-MSCs. (D) The levels of SOD1 mRNA (which encodes CuZn-SOD) in BM-MSCs were determined by real-time RT-PCR. (E) The levels of SOD2 mRNA (which encodes $\mathrm{Mn}-\mathrm{SOD}$ ) in BM-MSCs were determined by real-time RT-PCR. (F) The levels of SOD1/CUZn-SOD and SOD2/Mn-SOD protein were analyzed by western blotting analysis; glyceraldehyde-3-phosphate dehydrogenase (GAPDH) served as a loading control. Melatonin treatment significantly increased the expression of both SOD proteins. (G) The intensity of bands was measured using the ImageJ Software and the levels of expression of SOD1/CUZn-SOD and SOD2/Mn-SOD were normalized to the level of expression of GAPDH. Data are expressed as the mean \pm s.E.M. of four independent experiments, except for data from western blotting analysis, which are expressed as the mean \pm s.E.M. of three independent experiments $(* P<0.05$ and $* * P<0.01)$. A full colour version of this figure is available via http://dx.doi.org/10.1530/JOE-14-0430.

Differentiated BM-MSCs were assayed for calcium deposition by Alizarin Red S stain (Fig. 5A). Growth on decellularized ECM enhanced calcium secretion by $61.9 \%$ compared with growth on TCPS. Melatonin supplementation increased the level of mineralization by
$33.1 \%$ in TCPS-cultured cells and by $30.5 \%$ in ECMcultured cells (Fig. 5B).

To evaluate the extent to which decellularized ECM modulated the effects of melatonin on osteogenic differentiation, the gene expression of osteoblast-specific markers in differentiated BM-MSCs was examined by
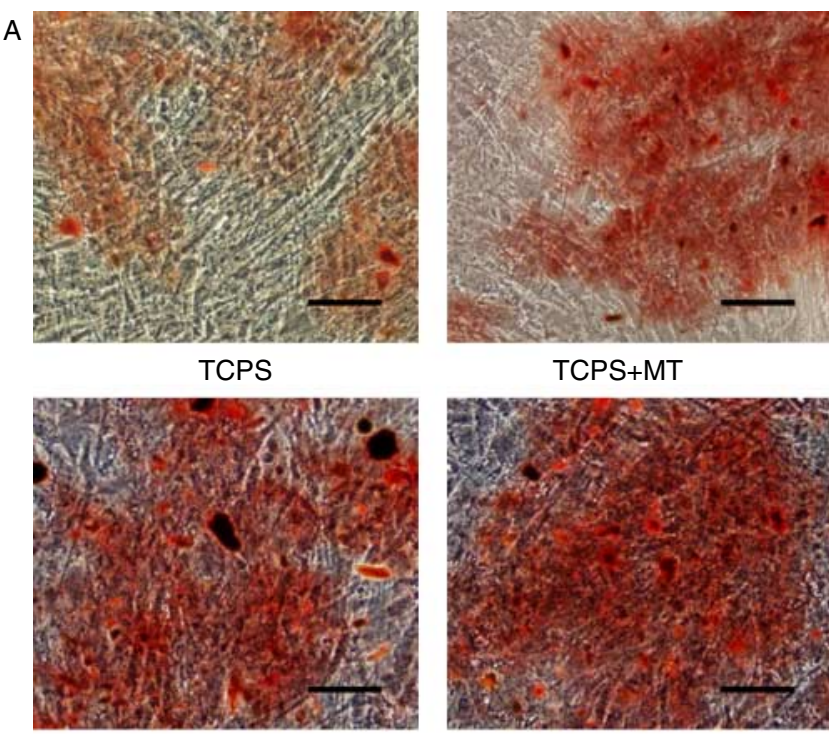

ECM

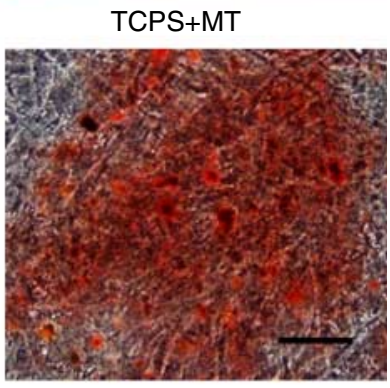

$\mathrm{ECM}+\mathrm{MT}$

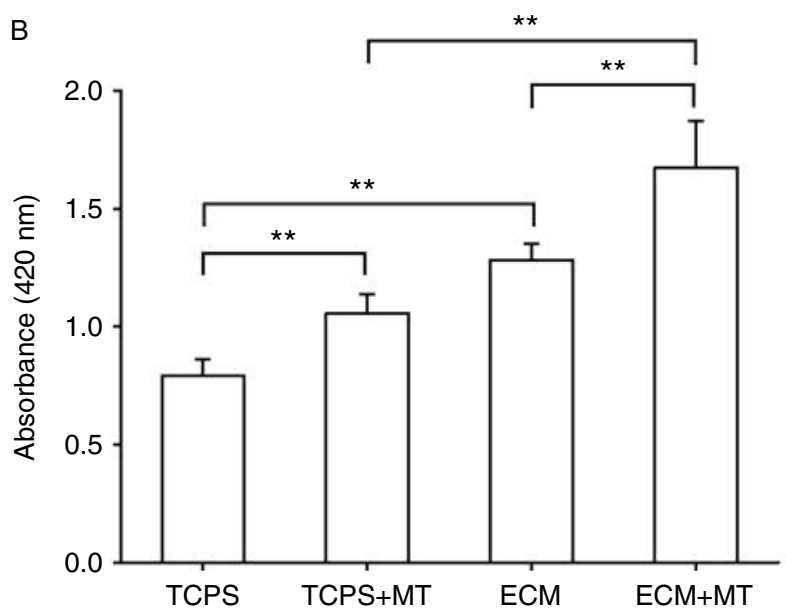

Figure 5

Decellularized extracellular matrix (ECM), when combined with melatonin, promoted calcium deposition in bone-marrow-derived mesenchymal stem cells (BM-MSCs) during osteogenic differentiation. (A) BM-MSCs were incubated in osteogenic differentiation medium for 14 days on tissue culture polystyrene (TCPS) or on decellularized ECM, with or without $100 \mu \mathrm{M}$ melatonin. Alizarin Red S staining was used to detect calcium secretion. Scale bars $=100 \mu \mathrm{m}$. (B) Quantification of the stained mineral layer, dissolved in $1 \%$ hydrochloric acid, determined using a spectrophotometer. Decellularized ECM significantly enhanced the effect of melatonin on calcium deposition. Data are expressed as the mean \pm s.E.M. of four independent experiments $(* * P<0.01)$. A full colour version of this figure is available via http://dx.doi.org/10.1530/JOE-14-0430. 
real-time RT-PCR. Melatonin treatment and growth on ECM increased the transcription of $A L P$ by 53.3 and $119.5 \%$, respectively, compared with growth on TCPS without melatonin (Fig. 6A). The expression of COL1A1 was $69.1 \%$ higher and $40.5 \%$ higher in melatonin-treated cells cultured on TCPS and on ECM, respectively, relative to the corresponding populations of untreated cells (Fig. 6B). Similarly, the levels of BGLAP (Fig. 6C) and SPP1 (Fig. 6D) transcription were significantly elevated when cells were grown on ECM and treated with
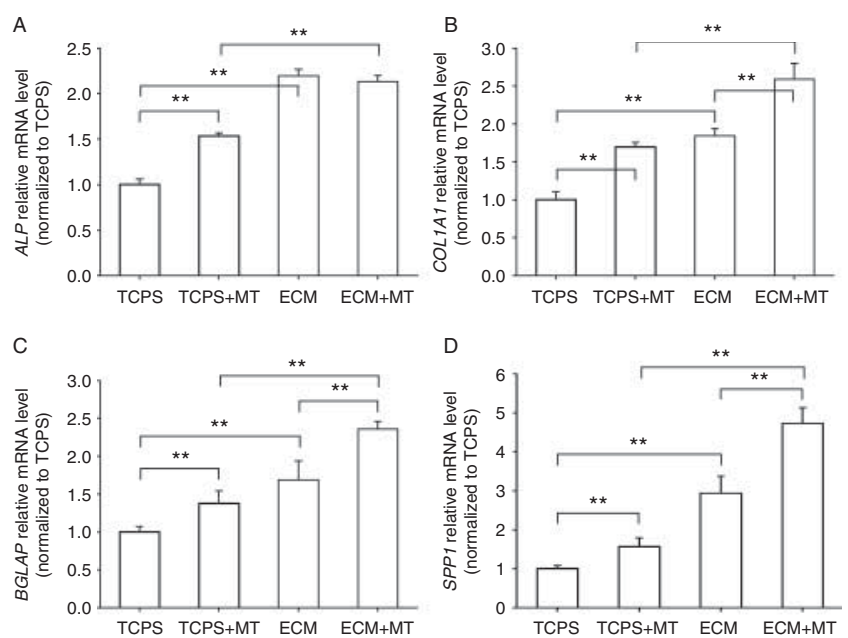

E
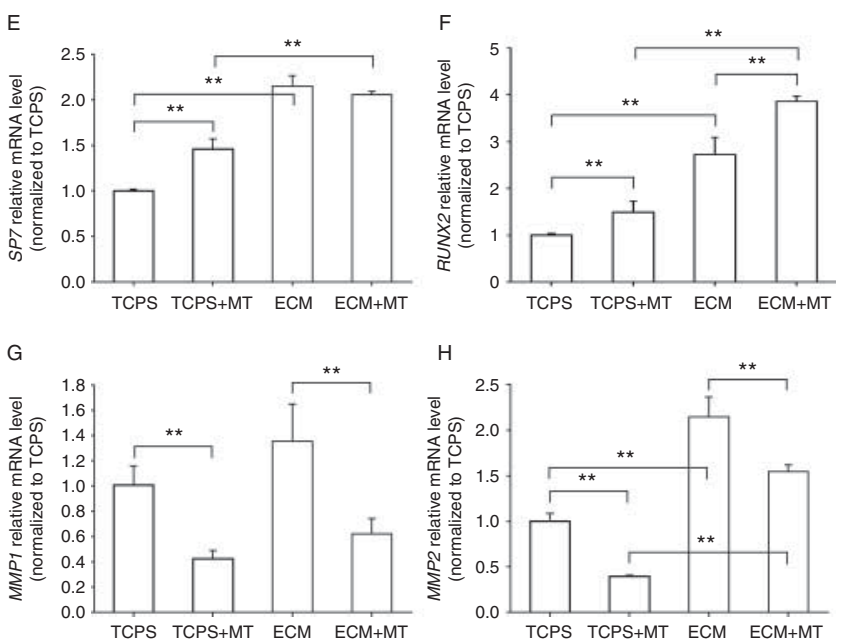

\section{Figure 6}

Decellularized extracellular matrix (ECM) modulates the effect of melatonin on the expression of mRNA encoding osteogenesis-specific markers and matrix degrading enzymes. The concentration of melatonin used was $100 \mu \mathrm{M}$. The mRNA levels of $A L P(A), C O L 1 A 1$ (B), BGLAP (C), SPP1 (D), $S P 7(\mathrm{E}), \operatorname{RUNX2}(\mathrm{F}), M M P 1(\mathrm{G})$, and $M M P 2(\mathrm{H})$ were measured by real-time RT-PCR. Decellularized ECM significantly enhanced melatonin-mediated effects on the transcription of osteogenic genes, while suppressing the levels of mRNAs encoding matrix metalloproteinases (MMPs). Data are expressed as the mean \pm S.E.M. of four independent experiments $(* * P<0.01)$. melatonin. The transcription factors Osterix and RUNX2, encoded by SP7 and RUNX2, respectively, are critical for osteogenesis. Melatonin treatment significantly increased the transcription of SP7 in TCPS-cultured cells by $45.7 \%$ (Fig. 6E) and up-regulated the expression of RUNX2 by $41.6 \%$ in ECM-cultured cells (Fig. 6F).

To assess the effect of melatonin on matrix-degrading enzymes, the expression of MMP1 and MMP2 was examined. Melatonin exposure significantly decreased MMP1 expression by 57.9 and $54.1 \%$ in the BM-MSCs grown on TCPS and on ECM, respectively (Fig. 6G). In the presence of melatonin, the transcription of MMP2 declined by $60.4 \%$ in the cells grown on TCPS and by $28.1 \%$ in the cells grown on ECM (Fig. $6 \mathrm{H}$ ).

\section{The role of SOD and oxidative stress in the pro-osteogenic effects of ECM-melatonin interaction}

To gain insights into the mechanisms involved in ECM modulation of melatonin-mediated effects on ROS and osteogenesis, we further investigated the role of intracellular antioxidant enzymes. Two specific SOD inhibitors, the SOD1/CuZn-SOD inhibitor DDC and the SOD2/MnSOD inhibitor 2-ME, were added individually to the cells grown on TCPS or ECM in the presence or absence of melatonin. Treatment with DDC slightly amplified oxidative stress in TCPS-cultured cells $(P>0.05$, Fig. 7A). Treatment with 2-ME was more potent, raising ROS levels by $25.6 \%$ in TCPS-cultured BM-MSCs relative to melatonin-treated, TCPS-cultured cells (Fig. 7B), and raising ROS levels by $45.7 \%$ in ECM-cultured cells compared with melatonin-treated ECM-cultured cells.

With regard to the expression of osteogenesis-specific genes, both DDC and 2-ME treatments inhibited osteogenic differentiation of BM-MSCs. In the presence of melatonin, treatment of TCPS-cultured cells with DDC and 2-ME resulted in down-regulation in the expression of $A L P$ by 33.8 and $45.5 \%$ respectively (Fig. 8 A). The level of $A L P$ expression in the BM-MSCs grown on ECM was 39.7 and $66.5 \%$ lower with DDC and 2-ME treatment, respectively, compared with melatonin treatment (Fig. 8B). The mRNA levels of COL1A1 (Fig. 8C and D), SPP1 (Fig. $8 \mathrm{E}$ and F), and RUNX2 (Fig. 8G and $\mathrm{H}$ ) exhibited the same tendency. Moreover, DDC and 2-ME treatments affected the expression of genes encoding MMPs. In TCPScultured cells, DDC treatment downregulated the transcription of MMP1 (Fig. 9A); however, the BM-MSCs grown on ECM had a 50.1\% higher level of MMP1 expression with DDC treatment, but a $69.9 \%$ lower level with 2-ME treatment (Fig. 9B). Supplementation with 2-ME slightly

Published by Bioscientifica Ltd. 

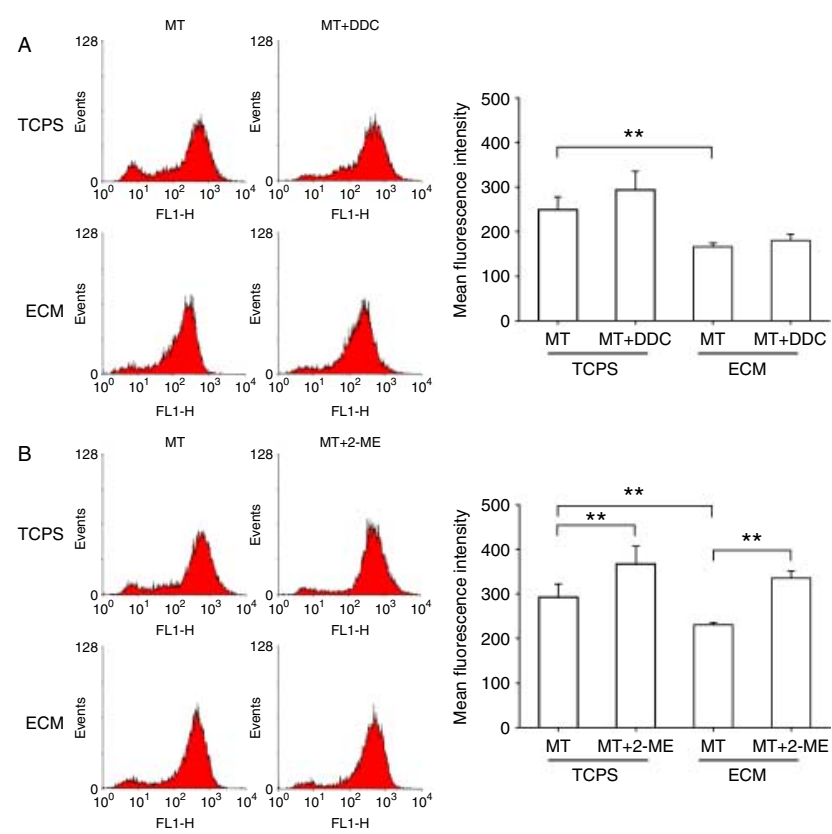

Figure 7

Treatment with superoxide dismutase (SOD) inhibitors affected oxidative stress in bone-marrow-derived mesenchymal stem cells (BM-MSCs) in the presence of extracellular matrix (ECM) and melatonin. (A) Production of intracellular reactive oxygen species (ROS) in BM-MSCs in the presence of diethyldithiocarbamate (DDC), an inhibitor of SOD1/CuZn-SOD. (B) Production of intracellular ROS by BM-MSCs in the presence of 2-methoxyestradiol (2-ME), an inhibitor of SOD2/Mn-SOD. Data are expressed as the mean \pm s.E.M. of four independent experiments $(* * P<0.01)$. A full colour version of this figure is available via http://dx.doi. org/10.1530/JOE-14-0430.

decreased the expression of MMP2 in TCPS-cultured BM-MSCs (Fig. 9C), but DDC treatment up-regulated the transcription of MMP2 by $43.7 \%$ in ECM-cultured BM-MSCs (Fig. 9D).

\section{Discussion}

Bone regeneration is triggered by the coordination of biochemical signals and the ECM microenvironment. Melatonin has been reported to stimulate osteogenic differentiation of MSCs; however, the role of native ECM in modulating the osteogenic effects of melatonin has not yet been explored. In this study, we characterized the matrix components and microstructure of cell-deposited ECM that mimicked the BM microenvironment. The adsorption of melatonin on ECM modulated the melatonin-mediated effects on cell proliferation, ROS levels, osteogenic maturation, and matrix degradation. For example, consistent with results from previous studies, we found that melatonin did not affect the growth of MSCs cultured on TCPS, but did improve the proliferation capacity of BM-MSCs cultured on decellularized ECM. The results of this study indicated that decellularized ECM provided a physiologically relevant microenvironment for investigating the biological functions of melatonin.

Decellularization of cell-deposited ECM also provides a facile method for rebuilding the stem cell niche and
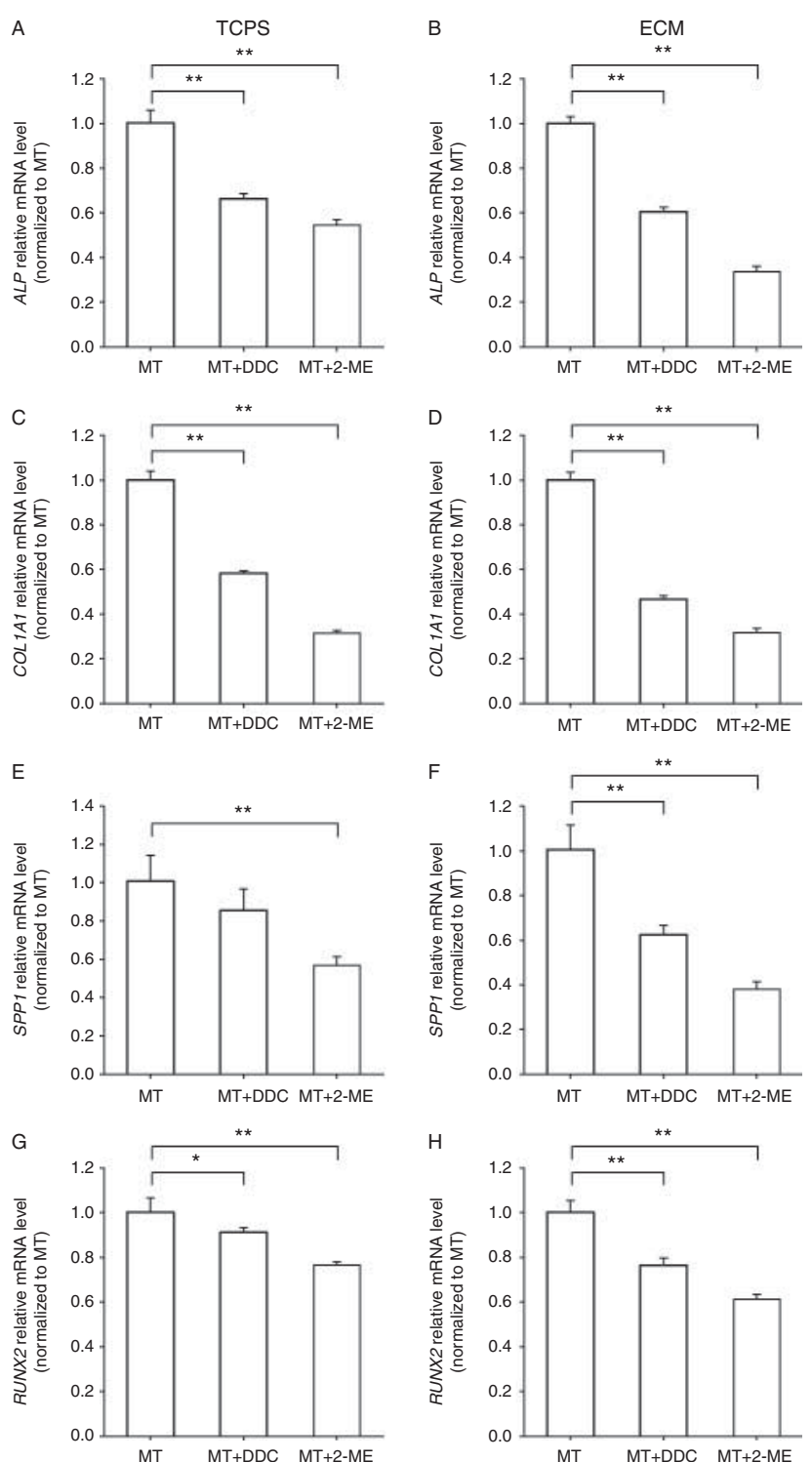

Figure 8

The effect of superoxide dismutase (SOD) inhibitors on gene expression of osteogenesis-specific markers, in differentiated bone-marrow-derived mesenchymal stem cells (BM-MSCs), in the presence of extracellular matrix (ECM) and melatonin. The mRNA levels of $A L P(A$ and $B), C O L 1 A 1(C$ and $D)$, SPP1 (E and F), and RUNX2 ( $\mathrm{G}$ and $\mathrm{H}$ ) were measured by real-time RT-PCR. Treatment with SOD inhibitors significantly suppressed the up-regulation of osteogenesis-specific marker genes by decellularized ECM and melatonin. Data are expressed as the mean \pm s.E.M. of four independent experiments $(* P<0.05$ and $* * P<0.01)$. 
A
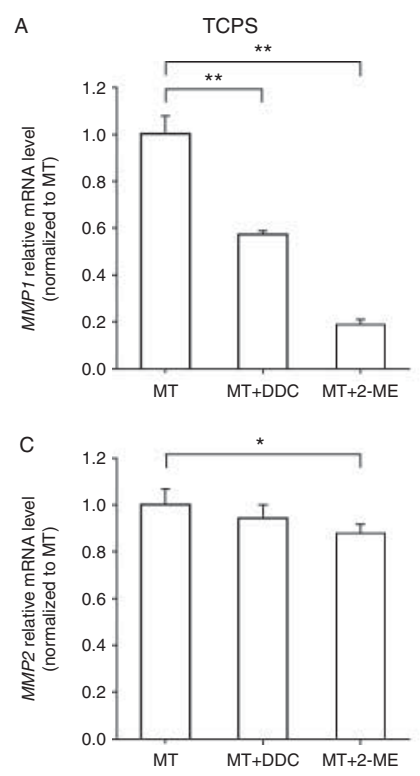

B
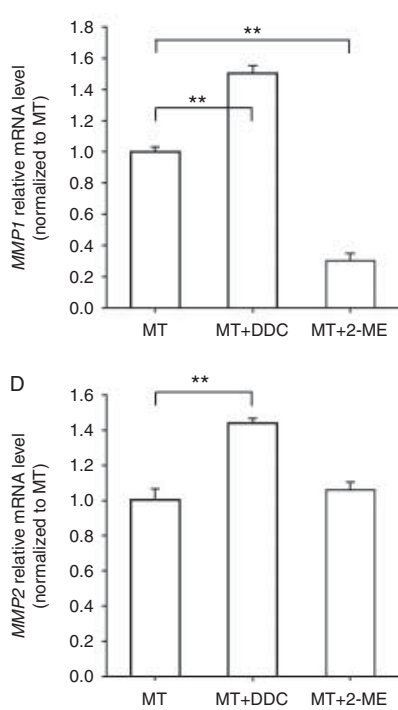

Figure 9

The effect of superoxide dismutase (SOD) inhibitors on gene expression of matrix metalloproteinases (MMPs) in differentiated bone-marrow-derived mesenchymal stem cells (BM-MSCs), in the presence of extracellular matrix (ECM) and melatonin. The mRNA levels of MMP1 (A and B) and MMP2

( $C$ and $D$ ) were measured by real-time RT-PCR. The application of diethyldithiocarbamate (DDC), an inhibitor of SOD1, reversed the suppressive effects of melatonin on MMP1 expression when BM-MSCs were cultured on decellularized ECM. Data are expressed as the mean \pm s.E.M. of four independent experiments $(* P<0.05$ and $* * P<0.01)$.

maintaining the characteristics of MSCs during in vitro expansion (Chen 2010). BM-MSCs that have been expanded on decellularized ECM display a strong expression of MSC-specific surface markers such as stagespecific embryonic antigen-4 (Pei et al. 2011). In addition, terminally differentiated cells such as articular chondrocytes (Pei \& He 2012) and nucleus pulposus cells (He \& Pei 2012) retain a robust capacity for re-differentiation on cell-deposited ECM, in contrast to their de-differentiated phenotypes in a conventional culture system. Furthermore, the superior biological performance of decellularized ECM coated on polymer-based scaffolds may be utilized in accelerating bone repair (Sadr et al. 2012).

Decellularized ECM has been proposed to mimic the in vivo stem cell niche that enhances self-renewal of MSCs, and it is believed that ECM provides a physiologically relevant $\mathrm{BM}$ microenvironment for BM-MSCs, thus increasing their sensitivity to exogenous chemicals such as melatonin. The composition of the ECM plays an important role in directing cell-matrix interactions and in regulating the binding of hormones, including melatonin. We found that the process of decellularization of celldeposited ECM preserved the native architecture of fibrillar collagens and a multiplicity of other matrix proteins. Type I collagen, which is retained after decellularization, is a major component of the BM ECM, and supports cell adhesion and growth by adsorbing and releasing growth factors (Hempel et al. 2012). The presence of fibronectin and type III collagen, which are responsible for the stimulation of BM-MSC replication (Maehata et al. 2007, Linsley et al. 2013), in decellularized ECM has been confirmed in a recent report using proteomics analysis ( $\mathrm{Li}$ et al. 2014). In addition, increases in integrin $\alpha_{2}$ levels have been observed in MSCs cultured on decellularized ECM (Pei et al. 2011); as a collagen receptor, integrin $\alpha_{2}$ may promote the osteogenic differentiation of BM-MSCs (Hu et al. 2013). However, further analyses are necessary to determine the key components in decellularized ECM that contribute to melatonin binding and, especially, to identify any low-weight proteoglycans that may play a role in melatonin adsorption to ECM.

Treatment with exogenous melatonin has been demonstrated, in previous studies, to promote osteoblast-specific gene expression in MSCs (Zhang et al. 2010); however, the simulating effect of hormones on lineage-specific differentiation of MSCs is influenced by their circumambient ECM (Sun et al. 2011). For example, osteoblastic maturation of BM-MSCs is regulated by growth factors, cytokines, hormones, and other chemical signals secreted by the surrounding cells in the BM, such as osteocytes, osteoclasts, and adipocytes, into the ECM. In this study, the ECM enhanced the effects of melatonin on BM-MSC mineralization, an important process in bone development and, in combination with melatonin, increased mRNA expression of osteogenic markers, including RUNX2 and SP7, which encode essential transcription factors that regulate the expression of downstream genes responsible for skeletal development and bone formation (Franceschi \& Xiao 2003, Zhou et al. 2010).

The mechanisms underlying the enhancement of osteogenic differentiation by ECM with bound melatonin remain unclear. Our results indicated that one of the potential mechanisms could be the up-regulation of antioxidant enzymes that attenuated the accumulation of intracellular free radicals and ROS. Although ROS are necessary for initiating osteoblastic development (Wang et al. 2004), their overproduction not only results in cellular apoptosis but also impairs osteoblast maturation (Feng et al. 2013). Similarly, intracellular ROS play a dual role in melatonin-mediated cell proliferation. The intermediate levels of ROS generation stimulate myoblast proliferation via the activation of extracellular adenosine 5'-triphosphate (Sciancalepore et al. 2012); however, high

Published by Bioscientifica Ltd. 
levels of oxidative stress result in cell cycle arrest in the $G_{1}$, $\mathrm{S}$, or $\mathrm{G}_{2}$ phase (Barnouin et al. 2002). In this study, we found that ECM with bound melatonin elevated the activity and expression of SOD proteins, in particular that of SOD2/Mn-SOD, which protects mitochondria from free radicals and ROS generated as byproducts of the electron transport chain. In the presence of 2-ME, a SOD2 inhibitor, BM-MSCs showed a marked increase in ROS production and suppression of osteoblast-specific marker genes. This was consistent with the finding that stem cells from aged donors, with lower levels of SOD2, exhibited a loss of differentiation capacity (Pietila et al. 2012).

Beyond the modulation of expression of antioxidant enzymes, the ECM-melatonin interaction might affect osteogenesis by other mechanisms. Candidates for these additional modulation pathways include physiological processes that involve melatonin. Bone remodeling requires osteoclast-mediated bone resorption, which is regulated by melatonin. Administration of melatonin increases trabecular bone mass of young mice by inhibiting the resorptive functions of osteoclasts (Koyama et al. 2002), but this melatonin-mediated inhibition of bone resorption can also negatively affect the healing of bone fractures (Histing et al. 2012). The regulation of osteoclast activity by melatonin involves the suppression of the RANKL/RANK/OPG pathways, but may also involve the role of melatonin in scavenging free radicals, which act as important mediators during osteoclastogenesis of BM monocytes (Lee et al. 2005).

MMPs also play an important role in bone resorption and matrix degradation. MMP1 makes endogenous collagens more susceptible to destruction by other MMPs (Swarnakar et al. 2011), and MMP2 degrades partially denatured collagens and gelatin (Galasso et al. 2012). Knockdown of MMP1 results in a significant increase in osteogenic marker genes, while overexpression of MMP1 reverses this effect (Hayami et al. 2011). Our results revealed that ECM when combined with melatonin successfully suppressed the expression of MMP1 and MMP2. Therefore, it is possible that the ECM-melatonin combination protects BM-MSCs from proteolytic enzymes and prevents degradation of mineralized matrix during bone formation.

Another candidate process is angiogenesis. Angiogenesis is a crucial process during bone healing, as it promotes the formation of new bone tissue associated with blood vessels (Yamada et al. 2008). Melatonin not only exhibits anti-angiogenic effects on endothelial cells (Alvarez-García et al. 2013) and tumors (Kim et al. 2013) but also contributes to the early stages of neovascularization, and thus the accelerated mineralization of the bone matrix (Ramírez-Fernández et al. 2013).

Ultimately, the mechanisms underlying the promotion of osteogenic differentiation by melatonin entail binding to melatonin receptors, especially $\mathrm{MT}_{2}$ receptors, and binding induces the MAP kinase signaling cascade (Radio et al. 2006, Sethi et al. 2010). Blocking of melatonin receptors inhibits melatonin-mediated osteoblast development in humans (Liu et al. 2013), and suppresses the expression of antioxidant enzymes (Liu et al. 2014). Future work will explore connections between ECM and melatonin receptors.

Finally, the WNT/ $\beta$-catenin signaling pathway also controls MSC proliferation, differentiation, and bone formation (Luchetti et al. 2014). Melatonin enhances the osteogenic maturation of MC3T3-E1 cells via upregulation of $\beta$-catenin and $\mathrm{WNT} 5 \alpha / \beta$ and suppression of GSK-3 $\beta$, a typical negative regulator of canonical WNT/ $\beta$-catenin signaling (Park et al. 2011), while ECM induces a dramatic elevation of WNT5 $\alpha$ and WNT11, indicating that noncanonical WNT signaling is involved in cell proliferation and differentiation (Li et al. 2014). The role of WNT/ $\beta$-catenin signaling in ECM-modulated biological actions of melatonin is an obvious topic for future studies.

In conclusion, ECM provides a novel platform for studying the biological actions of melatonin in a physiologically relevant microenvironment that is composed of a BM-like microstructure and complexes of matrix proteins. Decellularized ECM binds to melatonin in the culture medium and modulates the effects of melatonin on cell proliferation, expression and activity of antioxidant enzymes, and intracellular oxidative stress in BM-MSCs. The ECM-melatonin combination improves the differentiation of human BM-MSCs into osteoblasts and suppresses the levels of MMPs, thereby preventing degradation of the calcified matrix. These results highlight the importance of native ECM in modulating the biological effects of growth factors or hormones; more importantly, they indicate that ECM in combination with melatonin can be employed in improving bone graft substitutes via MSC-based tissue engineering.

\section{Declaration of interest}

The authors declare that there is no conflict of interest that could be perceived as prejudicing the impartiality of the research reported.

\section{Funding}

This work was supported by the National Natural Science Foundation of China (nos 51203194, 51103182, 51373112, 11072165, and 21204056);

Published by Bioscientifica Ltd. 
Specialized Research Fund for the Doctoral Program of Higher Education (20120171120034); Guangdong Natural Science Foundation (no. S2012040007933); Natural Science Foundation of Jiangsu Province (nos BK20140323 and BK2012173); and Scientific Research Foundation for the Returned Overseas Chinese Scholars, State Education Ministry.

\section{Author contribution statement}

$\mathrm{F} \mathrm{H}$ and $\mathrm{X} \mathrm{L}$ designed the study, performed experiments, and wrote the manuscript. $L Z$ performed the western blotting analysis and analyzed the data. $K X, S C, G P$, and $W C$ participated in carrying out experiments, analyzing data, and revising the manuscript. Z-P $L$ and $M P$ participated in the conception of the study and revision of the manuscript. $Y \mathrm{G}$ designed the study and wrote the manuscript. All authors approved the final version to be published.

\section{References}

Alvarez-García V, González A, Alonso-González C, Martínez-Campa C \& Cos S 2013 Antiangiogenic effects of melatonin in endothelial cell cultures. Microvascular Research 87 25-33. (doi:10.1016/j.mvr.2013. 02.008)

Barnouin K, Dubuisson ML, Child ES, Fernandez de Mattos S, Glassford J, Medema RH, Mann DJ \& Lam EW $2002 \mathrm{H}_{2} \mathrm{O}_{2}$ induces a transient multi-phase cell cycle arrest in mouse fibroblasts through modulating cyclin D and p21 ${ }^{\text {Cip1 }}$ expression. Journal of Biological Chemistry $\mathbf{2 7 7}$ 13761-13770. (doi:10.1074/jbc.M111123200)

Bhat A, Boyadjiev SA, Senders CW \& Leach JK 2011 Differential growth factor adsorption to calvarial osteoblast-secreted extracellular matrices instructs osteoblastic behavior. PLOS ONE 6 e25990. (doi:10.1371/ journal.pone.0025990)

Cardinali DP, Ladizesky MG, Boggio V, Cutrera RA \& Mautalen C 2003 Melatonin effects on bone: experimental facts and clinical perspectives. Journal of Pineal Research 34 81-87. (doi:10.1034/j.1600-079X.2003. 00028.x)

Chen XD 2010 Extracellular matrix provides an optimal niche for the maintenance and propagation of mesenchymal stem cells. Birth Defects Research. Part C, Embryo Today: Reviews 90 45-54. (doi:10.1002/bdrc. 20171)

Chen XD, Dusevich V, Feng JQ, Manolagas SC \& Jilka RL 2007 Extracellular matrix made by bone marrow cells facilitates expansion of marrow-derived mesenchymal progenitor cells and prevents their differentiation into osteoblasts. Journal of Bone and Mineral Research 22 1943-1956. (doi:10.1359/jbmr.070725)

Dumay A, Rincheval V, Trotot P, Mignotte B \& Vayssiere JL 2006 The superoxide dismutase inhibitor diethyldithiocarbamate has antagonistic effects on apoptosis by triggering both cytochrome $c$ release and caspase inhibition. Free Radical Biology \& Medicine $\mathbf{4 0}$ 1377-1390. (doi:10.1016/j.freeradbiomed.2005.12.005)

Feng YF, Wang L, Zhang Y, Li X, Ma ZS, Zou JW, Lei W \& Zhang ZY 2013 Effect of reactive oxygen species overproduction on osteogenesis of porous titanium implant in the present of diabetes mellitus. Biomaterials 34 2234-2243. (doi:10.1016/j.biomaterials.2012.12.023)

Franceschi RT \& Xiao G 2003 Regulation of the osteoblast-specific transcription factor, Runx2: responsiveness to multiple signal transduction pathways. Journal of Cellular Biochemistry 88 446-454. (doi:10.1002/jcb.10369)

Galasso O, Familiari F, De Gori M \& Gasparini G 2012 Recent findings on the role of gelatinases (matrix metalloproteinase-2 and -9) in osteoarthritis. Advances in Orthopedics 2012 834208. (doi:10.1155/ 2012/834208)

Hamilton R \& Campbell FR 1991 Immunochemical localization of extracellular materials in bone marrow of rats. Anatomical Record $\mathbf{2 3 1}$ 218-224. (doi:10.1002/ar.1092310210)
Hayami T, Kapila YL \& Kapila S 2011 Divergent upstream osteogenic events contribute to the differential modulation of MG63 cell osteoblast differentiation by MMP-1 (collagenase-1) and MMP-13 (collagenase-3). Matrix Biology 30 281-289. (doi:10.1016/j.matbio.2011.04.003)

He F \& Pei M 2012 Rejuvenation of nucleus pulposus cells using extracellular matrix deposited by synovium-derived stem cells. Spine $\mathbf{3 7}$ 459-469. (doi:10.1097/BRS.0b013e31821fcc64)

He F \& Pei M 2013 Extracellular matrix enhances differentiation of adipose stem cells from infrapatellar fat pad toward chondrogenesis. Journal of Tissue Engineering and Regenerative Medicine 7 73-84. (doi:10.1002/term.505)

He F, Chen X \& Pei M 2009 Reconstruction of an in vitro tissue-specific microenvironment to rejuvenate synovium-derived stem cells for cartilage tissue engineering. Tissue Engineering. Part A 15 3809-3821. (doi:10.1089/ten.tea.2009.0188)

He H, Liu X, Peng L, Gao Z, Ye Y, Su Y, Zhao Q, Wang K, Gong Y \& He F 2013 Promotion of hepatic differentiation of bone marrow mesenchymal stem cells on decellularized cell-deposited extracellular matrix. BioMed Research International 2013 406871. (doi:10.1155/2013/406871)

Hempel U, Hintze V, Moller S, Schnabelrauch M, Scharnweber D \& Dieter P 2012 Artificial extracellular matrices composed of collagen I and sulfated hyaluronan with adsorbed transforming growth factor $\beta 1$ promote collagen synthesis of human mesenchymal stromal cells. Acta Biomaterialia 8 659-666. (doi:10.1016/j.actbio.2011.10.026)

Histing T, Anton C, Scheuer C, Garcia P, Holstein JH, Klein M, Matthys R, Pohlemann T \& Menger MD 2012 Melatonin impairs fracture healing by suppressing RANKL-mediated bone remodeling. Journal of Surgical Research 173 83-90. (doi:10.1016/j.jss.2010.08.036)

Hu HM, Yang L, Wang Z, Liu YW, Fan JZ, Fan J, Liu J \& Luo ZJ 2013 Overexpression of integrin a2 promotes osteogenic differentiation of hBMSCs from senile osteoporosis through the ERK pathway. International Journal of Clinical and Experimental Pathology 6 841-852.

Jiang Y, Jahagirdar BN, Reinhardt RL, Schwartz RE, Keene CD, OrtizGonzalez XR, Reyes M, Lenvik T, Lund T, Blackstad M et al. 2002 Pluripotency of mesenchymal stem cells derived from adult marrow. Nature 418 41-49. (doi:10.1038/nature00870)

Kim KJ, Choi JS, Kang I, Kim KW, Jeong CH \& Jeong JW 2013 Melatonin suppresses tumor progression by reducing angiogenesis stimulated by HIF-1 in a mouse tumor model. Journal of Pineal Research 54 264-270. (doi:10.1111/j.1600-079X.2012.01030.x)

Kotlarczyk MP, Lassila HC, O'Neil CK, D'Amico F, Enderby LT, WittEnderby PA \& Balk JL 2012 Melatonin osteoporosis prevention study (MOPS): a randomized, double-blind, placebo-controlled study examining the effects of melatonin on bone health and quality of life in perimenopausal women. Journal of Pineal Research 52 414-426. (doi:10.1111/j.1600-079X.2011.00956.x)

Koyama H, Nakade O, Takada Y, Kaku T \& Lau KH 2002 Melatonin at pharmacologic doses increases bone mass by suppressing resorption through down-regulation of the RANKL-mediated osteoclast formation and activation. Journal of Bone and Mineral Research 17 1219-1229. (doi:10.1359/jbmr.2002.17.7.1219)

Lee NK, Choi YG, Baik JY, Han SY, Jeong DW, Bae YS, Kim N \& Lee SY 2005 A crucial role for reactive oxygen species in RANKL-induced osteoclast differentiation. Blood 106 852-859. (doi:10.1182/blood-2004-09-3662)

Li J, Hansen KC, Zhang Y, Dong C, Dinu CZ, Dzieciatkowska M \& Pei M 2014 Rejuvenation of chondrogenic potential in a young stem cell microenvironment. Biomaterials 35 642-653. (doi:10.1016/ j.biomaterials.2013.09.099)

Linsley C, Wu B \& Tawil B 2013 The effect of fibrinogen, collagen type I, and fibronectin on mesenchymal stem cell growth and differentiation into osteoblasts. Tissue Engineering. Part A 19 1416-1423. (doi:10.1089/ ten.tea.2012.0523)

Liu X, Gong Y, Xiong K, Ye Y, Xiong Y, Zhuang Z, Luo Y, Jiang Q \& He F 2013 Melatonin mediates protective effects on inflammatory response induced by interleukin-1 $\beta$ in human mesenchymal stem cells. Journal of Pineal Research 55 14-25. (doi:10.1111/jpi.12045) 
Liu X, Xu Y, Chen S, Tan Z, Xiong K, Li Y, Ye Y, Luo ZP, He F \& Gong Y 2014 Rescue of proinflammatory cytokine-inhibited chondrogenesis by the antiarthritic effect of melatonin in synovium mesenchymal stem cells via suppression of reactive oxygen species and matrix metalloproteinases. Free Radical Biology \& Medicine 68 234-246. (doi:10.1016/ j.freeradbiomed.2013.12.012)

Lopez-Martinez F, Olivares Ponce PN, Guerra Rodriguez M \& Martinez Pedraza R 2012 Melatonin: bone metabolism in oral cavity. International Journal of Dentistry 2012 628406. (doi:10.1155/2012/ 628406)

Luchetti F, Canonico B, Bartolini D, Arcangeletti M, Ciffolilli S, Murdolo G, Piroddi M, Papa S, Reiter RJ \& Galli F 2014 Melatonin regulates mesenchymal stem cell differentiation: a review. Journal of Pineal Research 56 382-397. (doi:10.1111/jpi.12133)

Maehata Y, Takamizawa S, Ozawa S, Izukuri K, Kato Y, Sato S, Lee MC, Kimura A \& Hata R 2007 Type III collagen is essential for growth acceleration of human osteoblastic cells by ascorbic acid 2-phosphate, a long-acting vitamin C derivative. Matrix Biology 26 371-381. (doi:10.1016/j.matbio.2007.01.005)

Park KH, Kang JW, Lee EM, Kim JS, Rhee YH, Kim M, Jeong SJ, Park YG \& Kim SH 2011 Melatonin promotes osteoblastic differentiation through the BMP/ERK/Wnt signaling pathways. Journal of Pineal Research $\mathbf{5 1}$ 187-194. (doi:10.1111/j.1600-079X.2011.00875.x)

Pei M \& He F 2012 Extracellular matrix deposited by synovium-derived stem cells delays replicative senescent chondrocyte dedifferentiation and enhances redifferentiation. Journal of Cellular Physiology 227 2163-2174. (doi:10.1002/jcp.22950)

Pei M, He F, Wei L \& Rawson A 2009 Melatonin enhances cartilage matrix synthesis by porcine articular chondrocytes. Journal of Pineal Research 46 181-187. (doi:10.1111/j.1600-079X.2008.00646.x)

Pei M, He F \& Kish VL 2011 Expansion on extracellular matrix deposited by human bone marrow stromal cells facilitates stem cell proliferation and tissue-specific lineage potential. Tissue Engineering. Part A 17 3067-3076. (doi:10.1089/ten.tea.2011.0158)

Pietila M, Palomaki S, Lehtonen S, Ritamo I, Valmu L, Nystedt J, Laitinen S, Leskela HV, Sormunen R, Pesala J et al. 2012 Mitochondrial function and energy metabolism in umbilical cord blood- and bone marrowderived mesenchymal stem cells. Stem Cells and Development 21 575-588. (doi:10.1089/scd.2011.0023)

Pittenger MF, Mackay AM, Beck SC, Jaiswal RK, Douglas R, Mosca JD, Moorman MA, Simonetti DW, Craig S \& Marshak DR 1999 Multilineage potential of adult human mesenchymal stem cells. Science $\mathbf{2 8 4}$ 143-147. (doi:10.1126/science.284.5411.143)

Poeggeler B, Reiter RJ, Tan DX, Chen LD \& Manchester LC 1993 Melatonin, hydroxyl radical-mediated oxidative damage, and aging: a hypothesis. Journal of Pineal Research 14 151-168. (doi:10.1111/j.1600-079X.1993. tb00498.x)

Radio NM, Doctor JS \& Witt-Enderby PA 2006 Melatonin enhances alkaline phosphatase activity in differentiating human adult mesenchymal stem cells grown in osteogenic medium via $\mathrm{MT}_{2}$ melatonin receptors and the MEK/ERK (1/2) signaling cascade. Journal of Pineal Research 40 332-342. (doi:10.1111/j.1600-079X.2006.00318.x)

Ramírez-Fernández MP, Calvo-Guirado JL, de-Val JE, Delgado-Ruiz RA, Negri B, Pardo-Zamora G, Peñarrocha D, Barona C, Granero JM \&
Alcaraz-Baños M 2013 Melatonin promotes angiogenesis during repair of bone defects: a radiological and histomorphometric study in rabbit tibiae. Clinical Oral Investigations 17 147-158. (doi:10.1007/ s00784-012-0684-6)

Sadr N, Pippenger BE, Scherberich A, Wendt D, Mantero S, Martin I \& Papadimitropoulos A 2012 Enhancing the biological performance of synthetic polymeric materials by decoration with engineered, decellularized extracellular matrix. Biomaterials 33 5085-5093. (doi:10.1016/j.biomaterials.2012.03.082)

Sanchez-Barcelo EJ, Mediavilla MD, Tan DX \& Reiter RJ 2010 Scientific basis for the potential use of melatonin in bone diseases: osteoporosis and adolescent idiopathic scoliosis. Journal of Osteoporosis 2010830231. (doi:10.4061/2010/830231)

Sciancalepore M, Luin E, Parato G, Ren E, Giniatullin R, Fabbretti E \& Lorenzon P 2012 Reactive oxygen species contribute to the promotion of the ATP-mediated proliferation of mouse skeletal myoblasts. Free Radical Biology \& Medicine 53 1392-1398. (doi:10.1016/j.freeradbiomed. 2012.08.002)

Sethi S, Radio NM, Kotlarczyk MP, Chen CT, Wei YH, Jockers R \& Witt-Enderby PA 2010 Determination of the minimal melatonin exposure required to induce osteoblast differentiation from human mesenchymal stem cells and these effects on downstream signaling pathways. Journal of Pineal Research 49 222-238. (doi:10.1111/ j.1600-079X.2010.00784.x)

Sun Y, Li W, Lu Z, Chen R, Ling J, Ran Q, Jilka RL \& Chen XD 2011 Rescuing replication and osteogenesis of aged mesenchymal stem cells by exposure to a young extracellular matrix. FASEB Journal 25 1474-1485. (doi:10.1096/fj.10-161497)

Swarnakar S, Paul S, Singh LP \& Reiter RJ 2011 Matrix metalloproteinases in health and disease: regulation by melatonin. Journal of Pineal Research 50 8-20. (doi:10.1111/j.1600-079X.2010.00812.x)

Tan DX, Manchester LC, Reiter RJ, Qi WB, Zhang M, Weintraub ST, Cabrera J, Sainz RM \& Mayo JC 1999 Identification of highly elevated levels of melatonin in bone marrow: its origin and significance. Biochimica et Biophysica Acta 1472 206-214. (doi:10.1016/S03044165(99)00125-7)

Wang FS, Yang KD, Wang CJ, Huang HC, Chio CC, Hsu TY \& Ou CY 2004 Shockwave stimulates oxygen radical-mediated osteogenesis of the mesenchymal cells from human umbilical cord blood. Journal of Bone and Mineral Research 19 973-982. (doi:10.1359/JBMR.040121)

Yamada Y, Tamura T, Hariu K, Asano Y, Sato S \& Ito K 2008 Angiogenesis in newly augmented bone observed in rabbit calvarium using a titanium cap. Clinical Oral Implants Research 19 1003-1009. (doi:10.1111/j.1600-0501.2008.01554.x)

Zhang L, Su P, Xu C, Chen C, Liang A, Du K, Peng Y \& Huang D 2010 Melatonin inhibits adipogenesis and enhances osteogenesis of human mesenchymal stem cells by suppressing PPAR $\gamma$ expression and enhancing Runx2 expression. Journal of Pineal Research 49 364-372. (doi:10.1111/j.1600-079X.2010.00803.x)

Zhou X, Zhang Z, Feng JQ, Dusevich VM, Sinha K, Zhang H, Darnay BG \& de Crombrugghe B 2010 Multiple functions of Osterix are required for bone growth and homeostasis in postnatal mice. PNAS $\mathbf{1 0 7}$ 12919-12924. (doi:10.1073/pnas.0912855107)

Received in final form 22 August 2014

Accepted 8 September 2014

Accepted Preprint published online 10 September 2014 http://joe.endocrinology-journals.org DOI: $10.1530 / \mathrm{JOE}-14-0430$
() 2014 Society for Endocrinology Printed in Great Britain 